\title{
Giant cell arteritis: the importance of immediate and appropriate diagnosis and treatment for better prognosis
}

This article was published in the following Dove Press journal:

Clinical Ophthalmology

II June 2012

Number of times this article has been viewed

\author{
Fernanda Pacella' \\ Francesco Mazzeo' \\ Dario Giorgi' \\ Francesco Cerutti' \\ David Impallara' \\ Giovanni Cuozzo' \\ Maurizio Soldini \\ Elena Pacella' \\ 'Department of Ophthalmology, \\ ${ }^{2}$ Service Detachment of Internal \\ Medicine and Cardiology, Department \\ of Ophthalmology, Sapienza University, \\ Rome, Italy
}

\begin{abstract}
This article describes the case of a 68-year-old patient suffering from giant cell arteritis (also known as Horton's arteritis or temporal arteritis). The patient came to our attention due to a large and sudden visual loss caused by the occlusion of major retinal arteries. The patient had neuralgic pain in the face. The next day, for a thorough examination, the patient went to the day hospital with a further worsening of the visual loss which required immediate admission to the ophthalmological ward for hospitalization lasting 10 days. During the observation period it was difficult to make an instant diagnosis due to the absence of clinical signs or diagnostic tests for Horton's arteritis. Only after the third day of hospitalization, when corticosteroid therapy was undertaken following the appearance of significant systemic symptoms, did the patient begin to show a gradual improvement in overall clinical status. The case highlights the difficulty in making a rapid diagnosis of giant cell arteritis and the efficacy of early steroid therapy in this vascular autoimmune disease that otherwise may result in irreversible functional and debilitating systemic damage.
\end{abstract}

Keywords: temporal arteritis, Horton's arteritis, corticosteroid

\section{Introduction}

Giant cell arteritis (GCA), also known as temporal arteritis or Horton's arteritis, is an inflammation T-lymphocyte mediated inflammation affecting the internal elastic lamina and external arteries of large and medium size. ${ }^{1}$ It is a medical emergency that can result in severe systemic and ocular complications. Among the latter the more problematic is the rapid and progressive loss of vision, which can also be bilateral and permanent. ${ }^{2}$

Typically, arteritic anterior ischemic optic neuropathy (A-AION) affects patients aged over 50 years; its incidence varies from 6.9 to 28.6/100,000 person-years and increases with age. ${ }^{3}$ It occurs more frequently in women and in Caucasians, with a higher incidence in Scandinavian countries and in Northern Europe, 30\%-50\%, and is associated with polymyalgia rheumatica. ${ }^{4}$

The etiology of A-AION remains unknown. It is a granulomatous vasculitis. The initial event is the activation of monocytes, probably following expression at the elastic lamina level, of exogenous and endogenous antigens; the whole process could be triggered by microbial infection, although there is still no scientific evidence that demonstrates this..$^{5}$ It has been suggested that there may be a genetic predisposition to the disease, as some studies have shown a correlation between giant cell arteritis and the major histocompatibility complex HLA-DR1, HLA-DR3, HLA-DR4 and HLA-DR5. Temporal arteritis can have different clinical manifestations and none of
Correspondence: Francesco Mazzeo Service Detachment of Internal Medicine and Cardiology, Department of Ophthalmology, Sapienza University, Rome, Italy Email pacella.ferny@libero.it 
these is pathognomonic; in fact, the same symptoms and signs may also occur in the case of other vessels in pathological processes. $^{6}$

Systemic symptoms usually precede the ophthalmological symptoms, but in some cases this may not occur. Peculiar systemic manifestations, which occur in about $90 \%$ of patients are headaches, typically within the temporal and occipital lobes, with or without fever (the latter very high, up to $39^{\circ} \mathrm{C}-40^{\circ} \mathrm{C}$ in $15 \%$ of cases $) .{ }^{7} \mathrm{Jaw}$ claudication, a temporal artery classic symptom caused by ischemia of the muscle and jaw, may be associated with pains in the face, tongue, gums, and ear and dizziness. ${ }^{6}$ The presence of symmetrical pain in the proximal muscles and the shoulder blades can warn of a mistaken diagnosis polymyalgia rheumatica. ${ }^{8}$

Neurological complications are: mononeuropathies and polyneuropathy of the upper and lower limbs, stroke, affecting more likely the patients who show visual deficit, and claudication of the jaw. ${ }^{9}$ The most serious ocular complication is severe visual impairment (about 20\% of patients), involving one or both eyes, with complete or partial forms. The loss of vision is mainly due to a large occlusion of the posterior ciliary arteries, less frequently to central retinal artery occlusion, and rarely occlusion of the ophthalmic artery. ${ }^{10}$ The irreversible loss of sight is often preceded by episodes of amaurosis fugax (about $30 \%$ of patients), triggered by a transient ischemia of the optic nerve head. ${ }^{6}$ In $50 \%$ of the affected eyes visual acuity will remain equivalent to hand motion or less, with a defect in the afferent papillary reflex. ${ }^{11}$ In the acute phase the optic disc appears pale, edematous, and gray, and two peripapillary hemorrhages are visible. The examination of the visual field shows a relative or absolute deficit. ${ }^{11}$

In total, $2 \%-15 \%$ of patients, even before visual loss, developed diplopia and ocular motility defects as a result of ischemia of the extraocular muscles, the nerves, and brain tissue. ${ }^{12}$ It is important to make a correct diagnosis, differentiating arteritic forms (A-AION) from non-arteritic anterior ischemic optic neuropathy (N-AION) forms, both, in fact, present with impaired vision, especially in elderly subjects. ${ }^{13}$ The first step is to exclude the temporal artery as a cause, seeking those who are at risk of the non-arteritic form (smoking, hypertension, diabetes mellitus, hyperlipidemia, migraine). N-AION forms are caused by occlusion or hypoperfusion of one or more branches of the short posterior ciliary arteries that supply the back portion of the laminar optic nerve. ${ }^{14}$ They do not lead to the onset of amaurosis fugax and alterations in blood tests and are not usually detected, in contrast to the A-AION forms. ${ }^{15}$
In addition, loss of vision in the A-AION forms is more rapid and severe than in the case of $\mathrm{N}-\mathrm{AION} .{ }^{14}$ The diagnosis of temporal arteritis is not always easy. Laboratory investigations are useful in confirming the diagnosis but only after biopsy of the temporal artery tissue. ${ }^{10}$ The American College of Rheumatologists in 1990 defined the criteria for the diagnosis of GCA, still considered the gold standard:

- Aged 50 years or over

- Headache of recent onset

- Swelling or tenderness to palpation or decreased temporal artery pulsatility

- Erythrocyte sedimentation rate $(\mathrm{ESR})>50 \mathrm{~mm} / \mathrm{hour}$

- Alteration to the artery with biopsy demonstrating vasculitis, characterized by a predominantly mononuclear infiltrate or granulomatous inflammation with multinucleated giant cells.

The diagnosis is made when at least three of the five criteria are met. The presence of three or more criteria had sensitivity of $93.5 \%$ and specificity of $91.2 \% .{ }^{15}$

ESR survey is the first laboratory test useful for diagnosis in patients whose GCA values are higher than normal, despite $10 \%-20 \%$ of patients remaining unchanged. ${ }^{16}$ It is important to rule out other causes that may affect ESR values such as inflammatory diseases, infections, and neoplasms. Another useful test is the C-reactive protein (CRP) test. CRP is an acute phase protein not affected by age or by the concomitant presence of hematological disorders. ESR is more sensitive for the diagnosis of GCA and more closely related to the positivity of the temporal artery biopsy. ${ }^{17}$ Neither ESR nor CRP are considered specific parameters of GCA, but are useful for monitoring the disease and response to drug therapy. Other laboratory abnormalities that may help in diagnosis are: the finding of thrombocytosis and positive anti-cardiolipin antibodies (about $50 \%$ of patients), and increased concentrations of interferon-gamma, interleukin-1B, and interleukin-6. ${ }^{17}$

The definitive diagnosis of temporal arteritis, however, can be made only by biopsy of the temporal artery; it is important that a biopsy is performed as soon as GCA is suspected, before starting the therapy. Positivity confirms the diagnosis, but in this case a negative result does not exclude it. Steroid therapy may reduce the chances of obtaining a positive result at biopsy, but the sensitivity is not significantly altered up to 2 weeks after starting therapy. Histologically the biopsy specimen is characterized by the presence of cellular infiltrates in the vessel wall and loss of internal elastic lamina. ${ }^{1}$

Radiological investigations are useful: magnetic resonance imaging, angiography, which usually shows irregularity and stenosis of the superficial temporary artery, and echo-color 
Doppler. ${ }^{11}$ Fluorescein angiography shows the typical defects relating to focal or generalized choroids; a massive lack of choroidal perfusion is typical of the A-AION forms. ${ }^{11}$

Therapy for GCA is based on the early use of corticosteroids, which reduce the inflammatory process in place and the risk of ischemic complications. The prognosis has been found to improve considerably once steroid therapy is introduced. ${ }^{18}$ Even despite high doses of steroids, deterioration of vision may occur at any time if the dosage is insufficient for the patient, or if steroid treatment is interrupted prematurely. ${ }^{11}$

Although much progress has been made towards understanding the pathogenesis of this disease, the cause remains unknown. ${ }^{19}$ GCA is a condition that can lead to blindness; currently, the only effective therapy remains steroid treatment, adequate but not ideal.

\section{Case presentation}

A 68-year-old female patient, following the occurrence of neuralgic pain in the face for about a week and a sudden drop in visual acuity in the right eye (RE), went (in July 2008) to the emergency room of our Ophthalmologic Department Center. During the in-depth medical history, she reported an acute episode of rash, facial edema, arthralgia, fever and claudication on mastication occurring 15 days earlier, was treated with betamethasone sodium phosphate, paracetamol, and Prixar $500 \mathrm{mg}$ tablets. The woman also reported that at that time the only vision correction she had been using was for reading, and that she had an allergy to painkillers; there were no references to previous operations or illnesses, including family history, worthy of note.

On the day of her arrival at the emergency room, an examination of her vision showed a best-corrected visual acuity perception of hand motion in RE, and 6/10 in the left eye (LE). Physical examination and ophthalmoscopy of the eye showed no significant alterations. The patient therefore was referred to a neurologist, but she refused to take up the referral.

The following day the woman went to the day hospital reporting a bilateral decrease in visual acuity which was confirmed by a re-examination of her vision: visual acuity through a pinhole in the RE was $2 / 10$, in the LE 3/10. A further examination of the fundus showed early signs of arterial occlusion with ischemic edema in the posterior pole and a macular cherry-red spot in the RE (Figure 1), with occlusion of the inferotemporal and superotemporal branches and of the central retinal artery sparing the macular area in the LE (Figure 2). She was then diagnosed with bilateral retinal arterial occlusion.

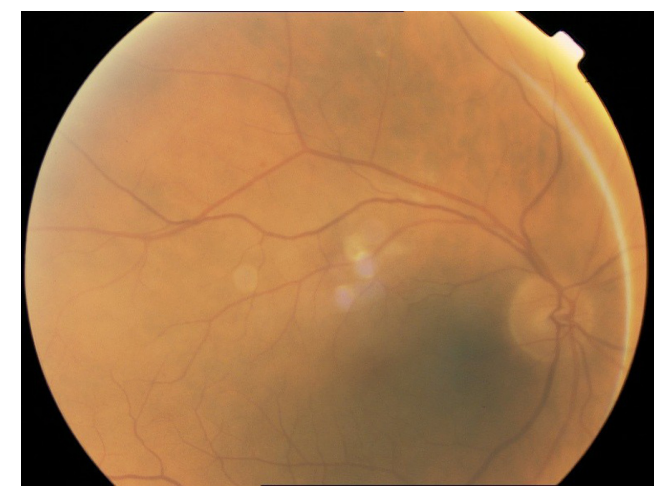

Figure I Picture of the fondus oculi with small ischemic areas.

We also conducted blood coagulation tests, which showed an increase in fibrinogen $(830 \mathrm{mg} / \mathrm{dL}$; reference range, 200-400 mg/dL); an optical coherence tomography was required, and an electrocardiogram performed, which showed incomplete right bundle branch block. On the basis of a hematological consult, nadroparin calcium 0.6 was administered subcutaneously every 12 hours and $100 \mathrm{mg}$ aspirin per day. It was also recommended that the patient be admitted to the ward for examination and treatment. On admission, the blood tests showed an ESR of $67 \mathrm{~mm} /$ hour (normal value $<35 \mathrm{~mm} /$ hour), CRP $19.4 \mathrm{mg} / \mathrm{dL}$ (normal value $<1 \mathrm{mg} / \mathrm{dL}$ ). Screening for thrombophilia showed heterozygous mutation of the prothrombin G20210A and heterozygous for methyltetrahydrofolate reductase (MTHFR C677T) mutation. An ultrasound of the neck vessels and an echocardiographic examination showed no significant alterations. During hospitalization, the patient was also subjected to retinal fluorescein angiography, was visited by an internist and by a cardiologist, and underwent a complete eye examination. Following the suggestion of the immunologist, a biopsy of the temporal artery was scheduled and carried out (5 cm in length). The histological examination showed an

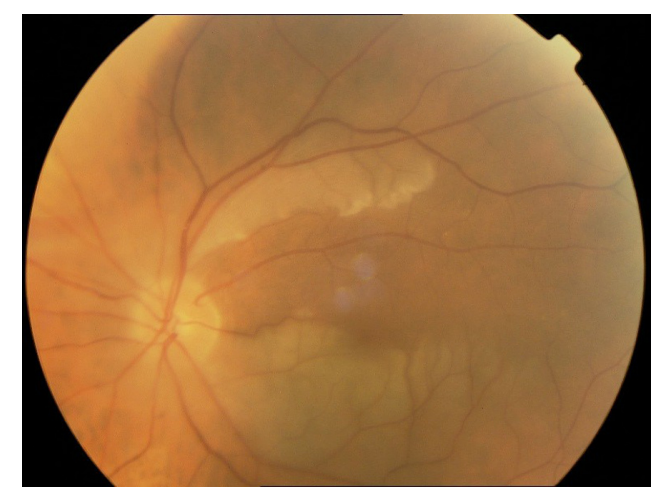

Figure 2 Fondus oculi-shows a more advanced stage of the ilness, where pailness of the optic disc and extended ischemic areas. 
infiltration of the tunica media made up of round and giant cells of Langhans type.

During the first 2 days of hospitalization the woman showed an improvement in LE visual acuity up to 9/10 with visual search through head movements.

On the third day of admission there was a rise in temperature $\left(38^{\circ} \mathrm{C}\right)$, bi-temporal headache and fatigue-type pain with polymyalgia to the pelvic girdle and therefore therapy was initiated with $25 \mathrm{mg}$ prednisone 2/day, replaced with soluble methylprednisolone $500 \mathrm{mg}$ 2/day, and $300 \mathrm{mg}$ ranitidine hydrochloride 1/day. From the sixth day, the patient showed a steady improvement in the symptoms and objective pathological findings. On the ninth day epigastric pain appeared, radiating to the right hemithorax, of 30 minutes' duration with spontaneous regression, for which an electrocardiogram was performed. An enzyme assay of myocardial necrosis did not show significant changes. In addition, a cardiology consult was sought, and a basic and stress myocardial scintigraphy was done in order to exclude coronary artery alterations. ${ }^{20}$

On the tenth day after admission the patient was discharged with the diagnosis of Horton's arteritis and the following therapy: prednisone $2 /$ day $\times 25 \mathrm{mg}$, ranitidine $300 \mathrm{mg} \times 1 /$ day, aspirin $1 /$ day $\times 100 \mathrm{mg}$, nadroparin calcium $0.6 \times 1 /$ day. At discharge vision in the $\mathrm{RE}$ with correction was 5/10; vision in the LE was $10 / 10$ with correction.

During the control week following discharge, blood tests showed a normalization of the parameters of nonspecific inflammation (ESR and CRP), and examination of the fundus showed a significant bilateral improvement; nadroparin calcium was suspended and corticosteroid therapy was increased gradually. Subsequent monthly checks confirmed a gradual and progressive improvement in symptoms and objective measures.

\section{Discussion}

Horton's disease is an autoimmune disease that preferentially affects the arteries of the neck and head and manifests itself in older age ( $>50$ years), with an incidence of about 15 new cases per 100,000 per year, affecting slightly more females than males. ${ }^{3}$ The manifestations are more often of systemic onset and nonspecific; temporal biopsy may be negative, and diagnosis is, therefore, difficult.

In a small percentage of cases the mode of onset may affect visual function with a sudden drop in visual acuity due to the acute and early involvement of the retinal vessels. Thanks to the clinical cases treated, what comes out is the difficulty in making the diagnosis of Horton's disease and the importance of early steroid therapy in the recovery of lost visual function. Because of the influence that corticosteroids have on the prognosis of visual function and prevention of other systemic manifestations in Horton's disease, it is advisable to use steroid therapy at the beginning of an attack in the absence of a definite diagnosis.

The loading dose in a case where GCA is suspected is $1 \mathrm{mg} / \mathrm{kg} /$ day; higher doses (80-100 g/day) can be administered in the case of patients with a severe decrease in visual acuity or cerebrovascular symptoms. In cases where the temporal biopsy is positive, steroid therapy is indispensable: 80-100 mg per day of prednisolone or intravenous corticosteroids ( $1 \mathrm{~g}$ methylprednisolone for 3 days) followed by high doses of prednisolone submitted orally. Once diagnosed and established, the dose of steroid therapy should be evaluated depending on the development of symptoms and laboratory tests. When there is remission of symptoms and the values of ESR and CRP have returned to normal, it is important to reduce the doses of steroid to scale: $10 \mathrm{mg} /$ day of prednisone for 6-9 months and 5 to $7.5 \mathrm{mg}$ /day for up to 1 year. High doses of steroids should be used with caution for their possible side effects, especially in patients with diabetes mellitus, hypertension, immunosuppression, duodenal ulcers, and glaucoma.

Treatment with corticosteroids, however, would seem to prevent a worsening, with only $13 \%$ of patients having had a worsening of vision loss.

All authors in the literature agree with the use of an appropriate steroid therapy in Horton's disease, beginning with full doses and continued for a long time. The correct steroid therapy has to be given according to the stage of disease, intensity, duration of ischemic phenomena district, the site, the changes in inflammatory markers, and with particular caution in patients with diabetes, hypertension, glaucoma, or osteoporosis.

Our case demonstrates once again the importance of timely and correct diagnosis and prompt therapeutic intervention that serves to modify the prognosis quoad functionem.

\section{Disclosure}

The authors report no conflicts of interest in this work.

\section{References}

1. Brack A, Geisler A, Martinez-Taboada VM, Younge BR, Goronzy JJ, Weyand CM. Giant cell vasculitis is a T cell-dependent disease. Mol Med. 1997;3:530-543.

2. Healey LA, Wilske KR. The Systemic Manifestations of Temporal Arteritis. New York: Grune and Stratton; 1978.

3. Paulley JW, Hugues JP. Giant cell arteritis, or arteritis of the aged. Br Med J. 1960;2:1562-1567. 
4. Bengtsson BA, Malvall BE. Prognosis of giant cell arteritis including temporal arteritis and polymyalgia rheumatica. Acta Med Scand. 1981;209:337-345.

5. O'Brien JP, Regan W. Actinically degenerate elastic tissue is the likely antigenic basis of actinic granuloma of the skin and of temporal arteritis. J Am Acad Dermatol. 1999;40:214-222. Review. Erratum in: J Am Acad Dermatol. 2000;42:148.

6. Healey LA, Kenneth R, Wilske KR. Manifestations of giant cell arteritis. Med Clin North Am. 1977;61:261-270.

7. Harrison MJG, Bevan AT. Early symptoms of temporal arteritis. Lancet. 1967;2:638-640.

8. Hamilton CK Jr, Shelley WM, Tumulty PA. Giant cell arteritis: including temporal arteritis and polymyalgia rheumatica. Medicine (Baltimore). 1971;50:1-27.

9. Moore PM, Cupps TR. Neurological complications of vasculitis. Ann Neurol. 1983;14:155-167.

10. Wilk A, Kazimierczuk K. Optic nerve neuropathy in the course of giant cell arteritis [review]. Klin Oczna. 2003;105:217-220. Polish.

11. Biendorf L, Worthen DM. Giant cell arteritis: a preventable cause of blindness. South Med J. 1974;67:85-86.

12. Lockshin MD. Diplopia as early sign of temporal arteritis. Report of two cases. Arthritis Rheum. 1970;13:419-421.
13. Hayreh SS. Anterior ischemic optic neuropathy. Arch Neurol. 1981;38: 675-678.

14. Miller NR. Anterior ischemic optic neuropathy: diagnosis and management. Bull N Y Acad Med. 1980;56:643-654.

15. Glaser JS. How to recognize ischemic optic neuropathy and what to do about it. Geriatrics. 1978;33:68-75.

16. Ciccarelli M, Jeanmonod D, Jeanmonod R. Giant cell temporal arteritis with a normal erythrocyte sedimentation rate: report of a case. $\mathrm{Am} \mathrm{J}$ Emerg Med. 2009;27:255, e1-e3.

17. Costello F, Zimmerman MB, Podhajsky PA, Hayreh SS. Role of thrombocytosis in diagnosis of giant cell arteritis and differentiation of arteritic from non-arteritic anterior ischemic optic neuropathy. Eur J Ophthalmol. 2004;14:245-257.

18. Danesh-Meyer HV, Savino PJ. Giant cell arteritis. Curr Opin Ophthalmol. 2007;18:443-449.

19. Sciacca A, Di Giacomo V, Carmenini G. Le Arteriopatie ad Impronta Flogistica. Rome, Italy: Edizioni Pozzi; 1981. Italian.

20. Soldini M, Gueli N, Toto A, Trua G, Carmenini G. L'interessamento cardiaco nella malattia di Horton. Ann Ital Med Int. 1987;2:229-235. Italian.
Clinical Ophthalmology

\section{Publish your work in this journal}

Clinical Ophthalmology is an international, peer-reviewed journal covering all subspecialties within ophthalmology. Key topics include: Optometry; Visual science; Pharmacology and drug therapy in eye diseases; Basic Sciences; Primary and Secondary eye care; Patien Safety and Quality of Care Improvements. This journal is indexed on

Submit your manuscript here: http://www.dovepress.com/clinical-ophthalmology-journal

\section{Dovepress}

PubMed Central and CAS, and is the official journal of The Society of Clinical Ophthalmology (SCO). The manuscript management system is completely online and includes a very quick and fair peer-review system, which is all easy to use. Visit http://www.dovepress.com/ testimonials.php to read real quotes from published authors. 